\title{
Sources de revenus et besoins d'accompagnement des exploitations agricoles familiales en zone cotonnière ouest du Burkina Faso
}

\author{
Mahamoudou Koutou ${ }^{(1)}$, Mamadou Sangaré ${ }^{(1)}$, Michel Havard ${ }^{(1,2)}$, Aurélie Toillier ${ }^{(1,2)}$, \\ Lacina Sanogo ${ }^{(1)}$, Taladidia Thombiano ${ }^{(3)}$, Davo Simplice Vodouhe ${ }^{(4)}$ \\ (1) Centre International de Recherche-Développement sur l'Élevage en zone Subhumide (CIRDES). Unité de Recherche sur \\ les Productions Animales (URPAN). 01 BP 454 Bobo-Dioulasso 01 (Burkina Faso).E-mail : madkout@yahoo.fr \\ (2) Centre de coopération Internationale en Recherche Agronomique pour le Développement (CIRAD). Unité Mixte de \\ Recherche Innovation et développement dans l'agriculture et l'alimentation. FR-34398 Montpellier (France). \\ (3) Université de Ouagadougou (UO2). Unité de Formation et de Recherche en Sciences Économiques et de Gestion (UFR/ \\ SEG). 11 BP 48. Ouagadougou 11 (Burkina Faso). \\ (4) Université d'Abomey Calavi au Bénin (UAC). Faculté des sciences agronomiques (FSA). Département d'Économie et \\ Socio-Anthropologie et de Communication pour le développement rural (DESAC). 01 BP 526. Cotonou (Bénin).
}

Reçu le 9 février 2015, accepté le 26 aout 2015.

Description du sujet. Dans la zone cotonnière ouest du Burkina Faso, la variabilité et la diversité des revenus des exploitations agricoles familiales (EAF) demandent pour ces dernières des accompagnements appropriés.

Objectifs. Cet article rend compte de cette diversité et des besoins d'accompagnement selon les types d'EAF identifiés.

Méthode. Les données ont été collectées par la méthode active de recherche participative et par enquête auprès d'un échantillon raisonné de 120 exploitations dans la commune de Koumbia. Une analyse en composante principale avec des indicateurs économiques de l'EAF suivie d'une classification ascendante hiérarchique ont été appliquées. Les caractéristiques structurelles, les pratiques de production agro-pastorales, les perceptions des chefs d'EAF sur les contraintes et opportunités de production agropastorale ont été comparées par une analyse de variance.

Résultats. Les résultats montrent trois types d'exploitations : les exploitations à faible revenu culture (agriculteurs), à fort revenu culture (agro-éleveurs) et à revenu élevage (éleveurs). À la lumière de leurs structures, pratiques de production, performances technico-économiques et opportunités de production agricole, leur accompagnement peut porter sur plusieurs innovations durables communes ou spécifiques des types identifiés. Des accompagnements sur la gestion des ressources de l'exploitation, les bonnes pratiques de gestion de la fertilité des sols et des animaux sont communs aux trois types d'EAF. Les cultures fourragères, l'embouche et la production laitière sont spécifiques aux agro-éleveurs et éleveurs. L'amélioration de la valeur nutritive des résidus de cultures et l'entretien des boufs de trait conviennent plus aux agriculteurs.

Conclusions. Pour réussir, le processus d'accompagnement doit prendre en compte ces spécificités et la notion de durabilité. Mots-clés. Intensification, exploitation agricole familiale, système d'exploitation agricole, durabilité, Afrique de l'Ouest.

Income source and accompaniment needs of family farms in the cotton growing area of West Burkina Faso

Description of the subject. In the western cotton growing area of Burkina Faso, the variability and the diversity of the income levels of family farms (EAFs) mean that these farms require suitable agronomic accompaniment.

Objectives. This article gives an account of this diversity and the need for accompaniment according to the type of identified EAF.

Method. The data were collected by the active method of participative research and by investigation of the practices of 120 farms in the commune of Koumbia. Principal component analyses with economic indicators of the EAF were applied, followed by an ascending hierarchical clustering. The structural characteristics, the agro-pastoral practices of production, and the perceptions of the EAF regarding the constraints and appropriateness of agricultural production were compared by variance analysis.

Results. The results showed three types of farm: farms with a low-income culture (farmers with few animals), those with a high income culture (farmers with a large number of animals) and those deriving income from breeding 
(stockbreeders). Taking into account the structure of the farms, their production practices, their technico-economic performance and their appropriateness of agricultural production, the form of sustainable accompaniment needed may be identified in relation to several common or specific innovations of the identified farm types. Accompaniments in the case of farm stock management, and good practice in the management of soil fertility and of animals were common to the three types of EAF. The fodder culture, fattening on pasture and the method of dairy production were specific to the farmers with a large number of animals and to the stockbreeders. The improvement of the food value of culture residues and of some aspects of the maintenance of oxen were more appropriate to the farmers with few animals.

Conclusion. In order to succeed, the process of accompaniment must take into account both these specificities and the concept of sustainability.

Keywords. Intensification, family farms, farming systems, sustainability, West Africa.

\section{INTRODUCTION}

En Afrique de l'Ouest, la productivité des cultures pluviales et de l'élevage reste en deçà des performances enregistrées dans d'autres parties du monde à conditions édaphiques et climatiques similaires (François, 2014). L'agriculture familiale, levier de croissance économique, y emploie plus de $60 \%$ de la population active. L'augmentation de sa productivité a longtemps été recherchée à travers le transfert vers les producteurs des paquets technologiques plus ou moins complexes élaborés dans les centres de recherches (Banque mondiale, 2008 ; Ferraton et al., 2009). Mais, ces dernières décennies, la vulgarisation agricole est interrogée sur sa capacité à répondre à des demandes nouvelles et diversifiées des exploitations agricoles familiales (EAF) (fertilisation organique, cultures fourragères, associations céréales légumineuses, agroforesterie, etc). Le caractère écologique et la diversité de ces demandes nécessite de réviser le contenu des appuis-conseils fournis aux EAF par divers acteurs (organisations paysannes, non gouvernementales, sociétés privées, etc.) suite au désengagement des États du secteur agricole (Faure, 2007).

Dans le bassin cotonnier de l'ouest du Burkina Faso, les EAF se sont organisées dès 1974 en groupements villageois $(\mathrm{GV})$, puis à partir de 1993 en groupements de producteurs de coton (GPC) fédérés depuis 1998 en Union Nationale des Producteurs de Coton du Burkina Faso (UNPCB). Elles bénéficient, à travers l'UNPCB et la Société des Fibres et Textiles du Burkina Faso (SOFITEX), de différents services, avec entre autres des crédits (engrais, herbicides, insecticides, semences, pulvérisateurs et tracteurs) et des actions de vulgarisation. Les crédits sont octroyés aux membres des GPC en fonction de la superficie coton à emblaver pour les intrants et pulvérisateurs et de la capacité de remboursement pour les tracteurs (cotonculteurs n'ayant pas d'impayés et produisant au moins $15 \mathrm{t}$ de coton graine par an). Les remboursements des crédits sont directement prélevés sur les recettes cotonnières lors de la campagne de commercialisation du coton graine en une année pour les intrants et pulvérisateurs et en cinq ans pour les tracteurs. En outre, les actions de vulgarisation portent surtout sur l'appui à la gestion et au fonctionnement des GPC par l'UNPCB, et sur les techniques culturales du cotonnier auprès des EAF par la SOFITEX pour produire massivement le coton, moteur de l'économie nationale (AICB, 2008). Ces actions de vulgarisation ne prennent pas (ou peu) en compte la diversité des EAF sur les plans techniques, économiques et sociaux (Capillon, 1993; Landais, 1996 ; IAC, 2004 ; Lankoandé, 2013).

Depuis 2003, la filière cotonnière africaine traverse une crise due aux adversités du climat (irrégularité des pluies), à la dégradation des ressources naturelles (baisse de la fertilité du sol, pression accrue des adventices et ravageurs du coton), à la baisse du cours mondial du coton et à l'augmentation du prix des intrants. Cette crise a été marquée au Burkina Faso entre les campagnes agricoles 2004-2005 et 2007-2008 par un déficit de 70 milliards de FCFA et une chute de $26 \%$ des revenus des producteurs (AICB, 2008). À cela s'ajoute la pression démographique. En effet, entre 1985 et 2014, la population de la commune de Koumbia a été multipliée par 5,11 avec une densité estimée à 55 habitants par $\mathrm{km}^{2}$, lorsqu'on soustrait la superficie des forêts classées qui sont inaccessibles aux populations (INSD, 2006; BEAER, 2014). Cette situation défavorable à l'activité agricole est accentuée par les phénomènes de la variabilité climatique (diminution de la durée de la saison des pluies, sècheresse, inondation, vents violents, forte température) et un environnement économique caractérisé par des fluctuations saisonnières des prix des produits agricoles et une augmentation des prix des facteurs de production (Ouédraogo et al., 2010). Pour mieux gérer ces risques climatiques et économiques, les EAF ont recomposé leurs activités et diversifié leurs productions agricoles (Traoré et al., 2013 ; Hathie et al., 2014). D'où la diversité de leurs sources de revenus, pratiques de production, structures et performances technico-économiques (Djouara et al., 2006 ; Blanchard et al., 2011 ; Phliponeau et al., 2011 ; Vall et al., 2011). Cette diversité des EAF demande de réfléchir à la prise en compte de leurs besoins divers d'accompagnement. Ce dernier fait référence aux processus d'apprentissage individuel et collectif pour 
maitriser les différentes facettes de leurs activités afin d'atteindre leurs divers objectifs familiaux (Faure, 2007).

Les typologies permettent d'appréhender plus facilement la diversité des EAF et donc d'analyser et comprendre l'agriculture, identifier des solutions, planifier des opérations de développement ou faire de la prospective (Faure, 2007).

Ces deux dernières décennies, de nombreuses études ont été conduites sur la diversité des EAF en zones cotonnières d'Afrique de l'Ouest et du Centre (Djouara et al., 2006 ; Vall et al., 2006 ; Mbetid-Bessane et al., 2013 ; Traoré et al., 2013). Elles montrent que les pratiques de gestion de la fertilité des sols et de l'alimentation du troupeau ont beaucoup évolué, mais aussi que les performances et les structures des EAF sont extrêmement variables selon les contextes. Les EAF font face à de nombreuses contraintes de production (pauvreté des sols, baisse des rendements, saturation du foncier rendant de plus en plus difficile l'accès à la terre, pluviosité en baisse et irrégulière, mécanisation partielle des techniques culturales, difficultés d'accès des animaux aux soins, à l'eau et à l'alimentation, faible niveau d'organisation des acteurs, conflits d'usage des ressources) (CIRDES, 2008 ; BEAER, 2014). Pour améliorer la productivité agricole et les revenus des producteurs, des solutions doivent être recherchées avec les producteurs prenant en compte les contraintes ci-dessus et la diversité des EAF (Vall et al., 2011 ; Coulibaly et al., 2012). L'hypothèse de cette recherche est que la connaissance des relations entre sources de revenus, performances technicoéconomiques, pratiques, contraintes et opportunités de production clarifient les besoins d'accompagnement des EAF. L'objectif de cet article est d'analyser la diversité des EAF et les besoins d'accompagnement tenant compte de cette diversité. L'analyse de la diversité des EAF s'appuie sur les revenus par source, les éléments de structure, les pratiques de production et les performances technico-économiques. Les contraintes et opportunités de production sont identifiées pour chaque type d'EAF afin de proposer des actions d'amélioration durables adaptées à chaque type d'EAF. Après un état de l'art sur les concepts clés utilisés dans l'article, nous présenterons la démarche méthodologique adoptée pour analyser la diversité des EAF suivie des résultats, d'une discussion et d'une conclusion.

\section{2. ÉTAT DE L'ART SUR LES CONCEPTS D'INTENSIFICATION DURABLE, ÉCOLOGIQUE ET AGRO-ÉCOLOGIQUE}

Les modèles d'agriculture technicistes et productivistes de la révolution verte (agriculture conventionnelle) ont montré leurs limites, en particulier en termes de durabilité écologique et économique (Chevassusau-Louis, 2006). Comment, dès lors, concevoir une agriculture à la fois plus productive (qui satisfait la demande croissante en produits agricoles) et plus durable (qui préserve les fonctions des écosystèmes nécessaires à sa propre viabilité et génère une valeur ajoutée environnementale) ? Le concept d' « intensification durable» vise à faire davantage de compromis entre des objectifs environnementaux et de production qui doivent être gérés dans le temps (produire plus à court terme tout en préservant les capacités productives des socio-agro-écosystèmes sur le long terme) (Chevassus-au-Louis et al., 2008). Le concept d'intensification écologique (IE) s'est invité dans le débat scientifique ces dernières années (Griffon, 2009). Il prend sa source dans celui de développement durable et cherche à rapprocher l'agronomie, l'écologie et les sciences sociales. C'est un système de production agro-sylvo-pastoral durable qui intègre plusieurs dimensions qui sont dialectiquement liées (culturelle, sociale, économique, écologique et politique). Elle allie la science moderne au savoir traditionnel, permet aux producteurs de transformer des exploitations agricoles à faible apport d'intrants ou de subsistance en systèmes plus productifs, tout en tirant davantage profit des ressources locales disponibles (FENAB, 2014). Au sens de Cassman (1999), elle est définie par le double objectif de continuer à augmenter les rendements tout en limitant les impacts négatifs des systèmes agricoles sur l'environnement. Cette définition fait peu référence aux moyens, mais beaucoup plus à la finalité : le développement durable (Landais, 1999). Selon Chevassus-au-Louis et al. (2008), l'IE vise à fonder des systèmes de production innovants, productifs et durables basés sur l'agro-écologie, en gérant les socio-agro-écosystèmes et en valorisant leurs services environnementaux, d'une manière interactive avec les contraintes socio-économiques évolutives des exploitations agricoles. L'agro-écologie étant considérée par certains chercheurs comme une discipline à part entière qui s'intéresse aux relations entre le fonctionnement du peuplement végétal et les différentes composantes des écosystèmes (Wezel et al., 2009), le concept «d'écologisation des pratiques » insiste sur le double objectif de réduire les externalités négatives de l'agriculture et de production de services environnementaux sans faire référence à l'accroissement de la production. En Afrique de l'Ouest, l'IE doit viser, en premier lieu, l'accroissement de la productivité de la terre par une valorisation efficace des ressources locales, sans pour autant écarter l'utilisation raisonnée et efficiente des intrants. Il a été montré que l'intégration agriculture-élevage est une option pour satisfaire production et efficience (Vayssières et al., 2011). 


\section{MATÉRIEL ET MÉTHODES}

\subsection{Zone d'étude}

L'étude a été réalisée dans une commune à forte pression foncière, Koumbia à l'Ouest du Burkina Faso (Figure 1). Située entre les isohyètes 800 et $1200 \mathrm{~mm}$, elle couvre une superficie de $1365 \mathrm{~km}^{2}$ dont $30 \%$ occupés par des forêts classées. Les zones pastorales et les pistes à bétail sont aujourd'hui cultivées, créant parfois des conflits entre agriculteurs et éleveurs. À partir des résultats du recensement général de la population et de l'habitat de 2006 et du taux de croissance démographique $(4,73 \%)$, la population de la commune de Koumbia est estimée à 52469 habitants en 2014 , dont $48,5 \%$ d'hommes et $51,5 \%$ de femmes (BEAER, 2014). Le coton, le maïs, le sorgho, le riz pluvial, l'arachide et le sésame sont les principales cultures. L'élevage de la commune de Koumbia est composé de bovins (21000 têtes), de petits ruminants
(32910 têtes), de porcins (9570 têtes), d'asins (810 têtes) et de volailles (26940 têtes) (BEAER, 2014). Le flux migratoire a augmenté les pressions sur les ressources. Les défrichements ont progressé

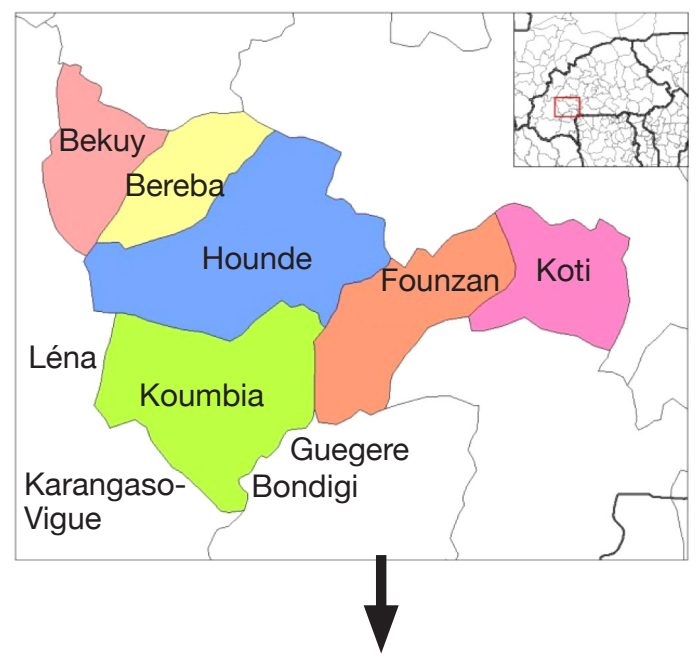

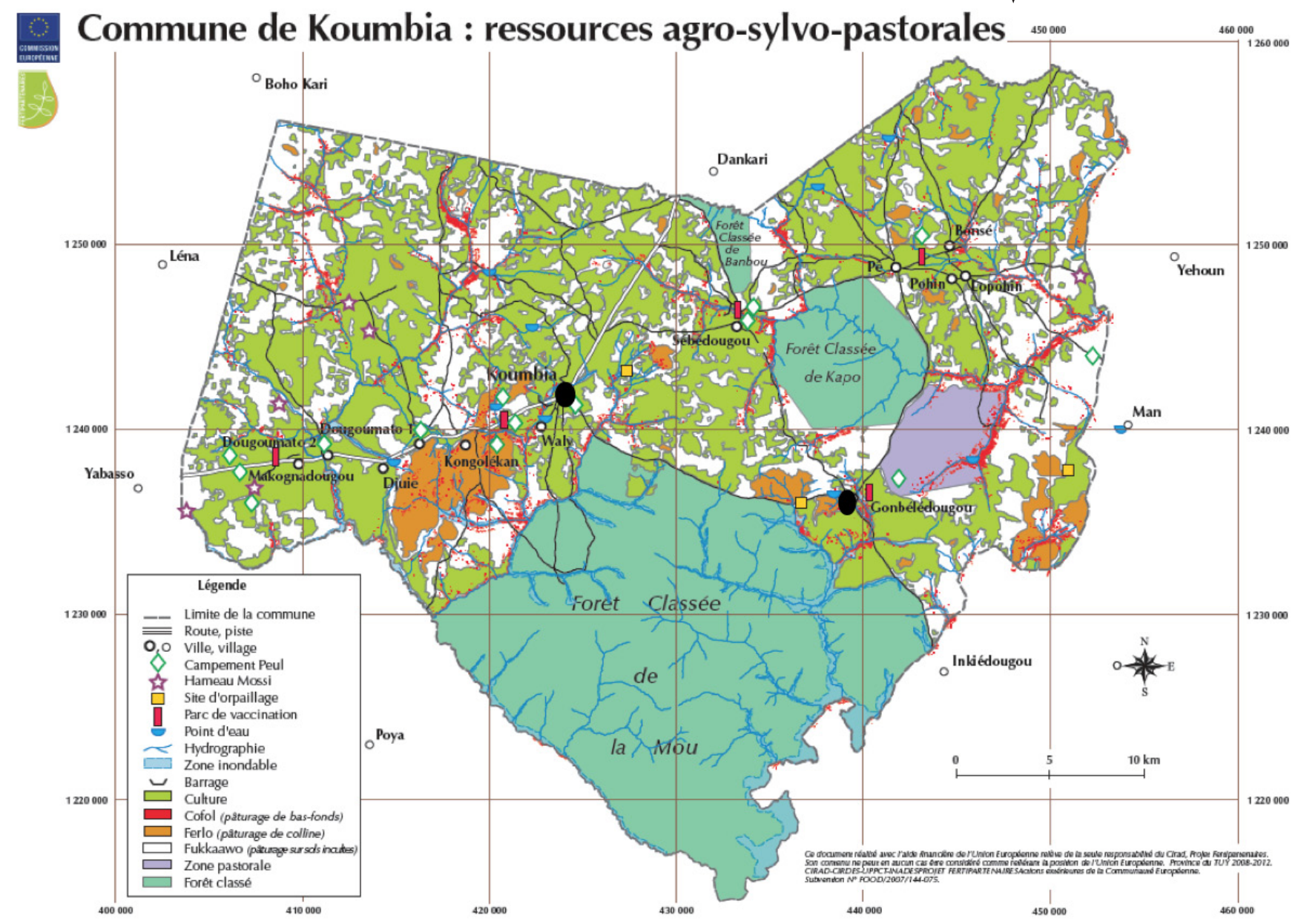

Sites d'études

Figure 1. Localisation des sites d'études - Localization of the study sites. 
rapidement : 20 à $30 \%$ des terres mis en cultures (Vall, 2004), faisant reculer les réserves sylvopastorales. Désormais, les parcelles sont cultivées en « continu », sans jachère, avec une dominance de la rotation cotonmaiis (Coulibaly et al., 2012). Les villages de Koumbia (11 185 habitants, 800 EAF) et de Gombèlèdougou (5310 habitants, $400 \mathrm{EAF}$ ), retenus pour la collecte des données, sont de grands foyers de la production cotonnière de la commune et d'intervention des projets et programmes.

Leurs EAF bénéficient des actions de vulgarisation et d'appuis-conseils de l'UNPCB, de la SOFITEX, des services techniques de l'État et des projets et programmes.

Le village de Koumbia est situé à $12^{\circ} 42^{\prime} 207^{\prime}$ 'N, $4^{\circ} 24^{\prime} 010^{\prime \prime} \mathrm{E}$ et Gombèlèdougou est à $12^{\circ} 21^{\prime} 66^{\prime \prime} \mathrm{N}$, 423'57''E.

\subsection{Collecte des données}

En plus de la recherche documentaire, les données ont été collectées en deux phases complémentaires dont l'une qualitative et l'autre quantitative.

Phase qualitative. Les données ont été obtenues à l'aide des outils (assemblée villageoise, focus group, transect) de la méthode active de recherche participative (MARP) pour identifier les principales cultures, le nombre et le type de groupements de producteurs, la composition du cheptel, les contraintes et opportunités de production. Ces résultats ont été restitués aux populations et ont servi de base pour l'élaboration du questionnaire et le choix de l'échantillon d'EAF à enquêter.

Phase quantitative. Un échantillon d'EAF a été choisi de façon raisonnée à partir des résultats de la phase qualitative et d'une typologie des EAF du village de Koumbia élaborée par Vall et al., 2006. Cette typologie est basée sur la superficie cultivée et le nombre de têtes de bovins de l'exploitation :

-agriculteurs: exploitants possédant moins de 10 bovins ;

- agro-éleveurs : exploitants possédant plus de 10 bovins et cultivant plus de 5 ha ;

- éleveurs : exploitants possédant plus de 10 bovins et cultivant moins de 5 ha.

Les groupements de producteurs identifiés dans chaque village lors de la phase qualitative ont constitué la base du sondage. Les EAF enquêtées ont été choisies parmi les membres des groupements de producteurs de coton (GPC) et d'éleveurs (GE), principales organisations de producteurs dans les villages. Pour tenir compte de la diversité des EAF, des agriculteurs cultivant moins de 5 ha, entre 5 ha et
15 ha et plus de 15 ha ont été choisis dans chaque GPC. Dans les GE, des éleveurs possédant 10 à 20 bovins et plus de 20 bovins ont été choisis. Au total, 120 EAF ont été enquêtées, soit $10 \%$ du nombre d'EAF de chaque village, représentatif pour les inférences statistiques (Christiaensen, 1998). Un questionnaire d'enquête élaboré par une équipe pluridisciplinaire (socio-économistes, agronomes et zootechniciens) a été soumis à chaque chef d'EAF. Il renseigne sur les caractéristiques générales et structurelles, les pratiques de production, les contraintes et opportunités de production agricole et l'économie de l'EAF.

\subsection{Cadre analytique}

Trois méthodes se révèlent les plus complètes et les plus utilisées pour comprendre l'organisation et le fonctionnement de l'exploitation agricole dans sa globalité : l'approche globale de l'exploitation agricole (AGEA), l'approche spatiale de l'exploitation agricole (ASEA) et la méthode guide d'étude de l'exploitation agricole (GEEA) (Abt et al., 2006). Le cadre analytique de cetteétude s'inscrit dans la méthode AGEA, car elle exige des informations diversifiées sur l'EAF. Elle cerne les activités de production végétale (cultures et vergers), animales (toutes espèces) et les activités extra-agricoles (pêche, chasse, orpaillage, artisanat, commerce, prestation de travail hors exploitation, dons ou transferts monétaires, etc.). Une analyse en composante principale (ACP) suivie d'une classification ascendante hiérarchisée $(\mathrm{CAH})$ a été appliquée aux indicateurs économiques de l'EAF comme les revenus culture, élevage, extra-agricole totaux rapportés au nombre d'actif pour regrouper les EAF selon leurs principales sources de revenus. Ces indicateurs ont été choisis car il existe une corrélation entre les performances technico-économiques, les pratiques de production et les structures des EAF dans la zone cotonnière (Traoré et al., 2013). Les moyennes des caractéristiques structurelles, des performances technico-économiques et des pratiques de production agropastorale de chaque classe ont été comparées par une analyse de variance (ANOVA) avec le test de Newman et Keuls au seuil de $5 \%$. Le test de $\chi^{2}$ a été utilisé pour analyser les tableaux de contingence.

Estimation des indicateurs technico-économiques. Parmi les indicateurs proposés dans la littérature pour évaluer les performances technico-économiques des EAF (Ferraton et al., 2009), le produit brut, la consommation intermédiaire, la valeur ajoutée, le revenu, les rendements, les productions de fumure organique (FO), de lait et les rations alimentaires ont été utilisés dans cette étude. Ils ont été calculés à l'aide des équations suivantes : 
$\forall$ le produit $p$ de l'exploitation

$\mathrm{PB}_{\text {expl }}=\Sigma\left[\left(\right.\right.$ Qté vendue $_{p}+$ Qté donnée $\left._{p}\right) \times$ Prix Vente $\left._{p}\right)+\left(\right.$ Qté autoconso $_{p} \times$ Prix Achat $\left.\left._{p}\right)\right]$

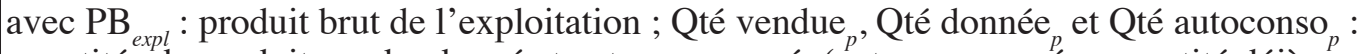

quantités de produit vendu, donné et autoconsommé, (autoconsommé = quantité déjà consommée

lors du passage des enquêteurs, quantité réservée pour la consommation future et pour les semences) ;

Prix Vente ${ }_{p}$ et Prix Achat ${ }_{p}$ : prix moyen local de vente et d'achat de $p$.

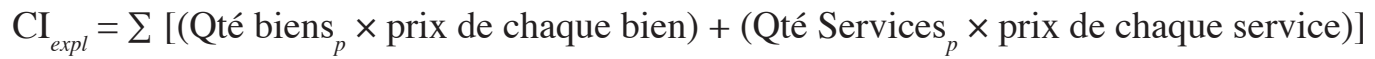

avec $\mathrm{CI}_{\text {expl }}$ : consommation intermédiaire de l'exploitation; Qté biens ${ }_{p}$ et Qté Services ${ }_{p}$ : quantités de biens et services nécessaires à la production de $p$.

$$
\begin{aligned}
& \mathrm{VAB}_{\text {expl }}=\sum \mathrm{VAB}_{p}=\mathrm{PB}_{\text {expl }}-\mathrm{CI}_{\text {expl }} \\
& \mathrm{VAN}_{\text {expl }}=\mathrm{VAB}_{\text {expl }}-\mathrm{A}
\end{aligned}
$$

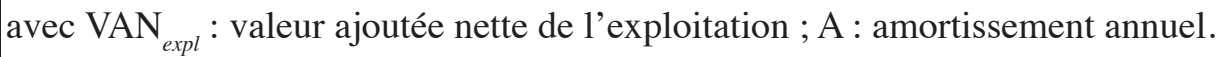

$\mathrm{REVENU} \mathrm{Net}_{\text {expl }}=\mathrm{VAN}_{\text {expl }}$ - subvention - salaire ouvriers - taxe - intérêt sur emprunt - rente foncière

Rendement $=\frac{\text { production totale }}{\text { superficie cultivée }}$

Déficit en Fumure organique (FO) = Quantité FO mobilisée - Besoins

avec Besoins en FO, égale à la superficie totale cultivée multipliée par 5 t matière sèche (selon la recommandation de la recherche par hectare tous les deux ans)

$$
\text { Quantité d'aliment distribué }=\frac{\text { quantité d'aliment mobilisé }}{\text { nombre d'Unité Bétail Tropical }}
$$

\section{RÉSULTATS}

\subsection{Caractéristiques générales des EAF}

Les résultats présentés dans le tableau 1 montrent que $98 \%$ des EAF sont gérées par des hommes. Sur l'ensemble des deux villages, $69 \%$ des chefs d'EAF sont propriétaires de leur plus grande superficie cultivée. Ce pourcentage est de $74 \%$ à Koumbia contre $60 \%$ à Gombèlèdougou $(p<0,05)$. Certains migrants de Koumbia se sont arrogés le droit de propriété en ne s'acquittant plus des droits symboliques annuels (céréales, poulets, etc.) du donateur. Près de $96 \%$ des chefs d'EAF prennent personnellement les décisions relatives au fonctionnement de l'EAF et plus de $99 \%$ sont mariés. Vingt-sept pourcent ont un niveau primaire et $19 \%$ ne savent ni lire, ni écrire. Seulement $17 \%$ ont reçu une formation en technique d'élevage et $15 \%$ en technique de production de la fumure organique $(p<0,1)$. Pour $72,5 \%$ des EAF à Gombèlèdougou et $31 \%$ à Koumbia, le sol de leur plus grande superficie cultivée est gravillonnaire $(p<0,001)$. Cinquante-deux et demi pourcent des EAF à Koumbia cultivent des sols sableux.

\subsection{Sources de revenus des EAF}

Les résultats de l'analyse en composante principale (Figure 2) montrent que $75 \%$ de la variabilité est expliquée par le plan factoriel composé des axes 1 et 2 représentant respectivement la production végétale et animale. L'axe 1 est formé par les variables revenu culture par actif et revenu total par actif et l'axe 2 par le revenu élevage par actif. La variable revenu extra-agricole par actif contribue à la formation des deux axes. La classification ascendante hiérarchique a permis d'identifier trois types d'EAF selon leurs sources de revenus. Le type $1(n=27)$ est composé des EAF qui tirent leurs revenus par ordre décroissant des cultures, des activités extra-agricoles et de l'élevage. Elles sont désignées comme EAF à fort revenu culture (agro-éleveurs). Le type $2(n=17)$ 
Tableau 1. Profils sociaux des exploitants agricoles - Social profiles of the farmers.

\begin{tabular}{|c|c|c|c|c|c|}
\hline Variables (\%) & Gombèlèdougou & Koumbia & Total & $\chi^{2}$ & $p$-value \\
\hline Sexe & & & & 1,01 & - \\
\hline Masculin & 100,0 & 97,5 & 98,33 & & \\
\hline Féminin & 0,0 & 2,5 & 1,66 & & \\
\hline Statut matrimonial & & & & 2,01 & - \\
\hline Marié & 97,5 & 100,0 & 99,16 & & \\
\hline Célibataire & 2,5 & 0,0 & 0,83 & & \\
\hline Niveau d'instruction & & & & 6,02 & - \\
\hline Analphabète & 25,0 & 16,25 & 19,16 & & \\
\hline Primaire & 17,5 & 31,25 & 26,66 & & \\
\hline Secondaire & 5,0 & 11,25 & 9,16 & & \\
\hline Ecole coranique & 27,5 & 27,5 & 27,5 & & \\
\hline Alphabétisé & 25,0 & 13,75 & 17,5 & & \\
\hline Gestionnaire de l'exploitation & & & & 2,5 & - \\
\hline Moi-même & 95,0 & 96,25 & 95,83 & & \\
\hline Enfant & 0,0 & 1,25 & 0,83 & & \\
\hline Frère & 0,0 & 1,25 & 0,83 & & \\
\hline Autres & 5,0 & 1,25 & 2,5 & & \\
\hline Statut de la grande parcelle cultivée & & & & 9,334 & $* *$ \\
\hline Propriétaire & 60,0 & 73,8 & 69,2 & & \\
\hline Locataire & 40,0 & 26,3 & 30,8 & & \\
\hline Type de sol dominant du grand champ & & & & 27,061 & $* * *$ \\
\hline Sableux & 5,0 & 52,5 & 36,7 & & \\
\hline Gravillonnaire & 72,5 & 31,3 & 45,0 & & \\
\hline Argileux & 22,5 & 16,3 & 18,3 & & \\
\hline Formation reçue & & & & 13,06 & * \\
\hline Aucune & 67,5 & 51,25 & 56,66 & & \\
\hline Production Fumure & 7,5 & 18,75 & 15,0 & & \\
\hline Production fourrage & 5,0 & - & 1,66 & & \\
\hline Technique d'élevage & 17,5 & 16,25 & 16,66 & & \\
\hline Bonne pratique agricole & - & 10,0 & 6,66 & & \\
\hline Autres & 2,5 & 3,75 & 3,32 & & \\
\hline
\end{tabular}

- : non significatif - not significant $; *: p<0,1 ; * *: p<0,05 ; * * *: p<0,001$.

constitué d'EAF qui tirent respectivement leurs revenus de l'élevage, des cultures et des activités extra-agricoles. Elles sont désignées comme des EAF à revenu élevage (éleveurs). Le type $3(n=76)$ est formé par les EAF moins nanties que le type 1 et qui tirent respectivement leurs revenus des cultures, des activités extra-agricoles et de l'élevage dans une moindre proportion que le type 1 . Ce sont des EAF à faible revenu culture (agriculteurs).

\subsection{Structure des EAF}

Comme le montre le tableau 2, les EAF se différencient significativement par la superficie cultivée $(p<0,001)$, la superficie cultivée par actif $(p<0,001)$, les nombres de champs $(p<0,001)$, de pulvérisateurs $(p<0,001)$, d'unités bétail tropical (UBT), de bœufs de trait $(p<0,001)$ et de charrues $(p<0,05)$. Ces variables sont positivement corrélées aux types d'EAF. Les 


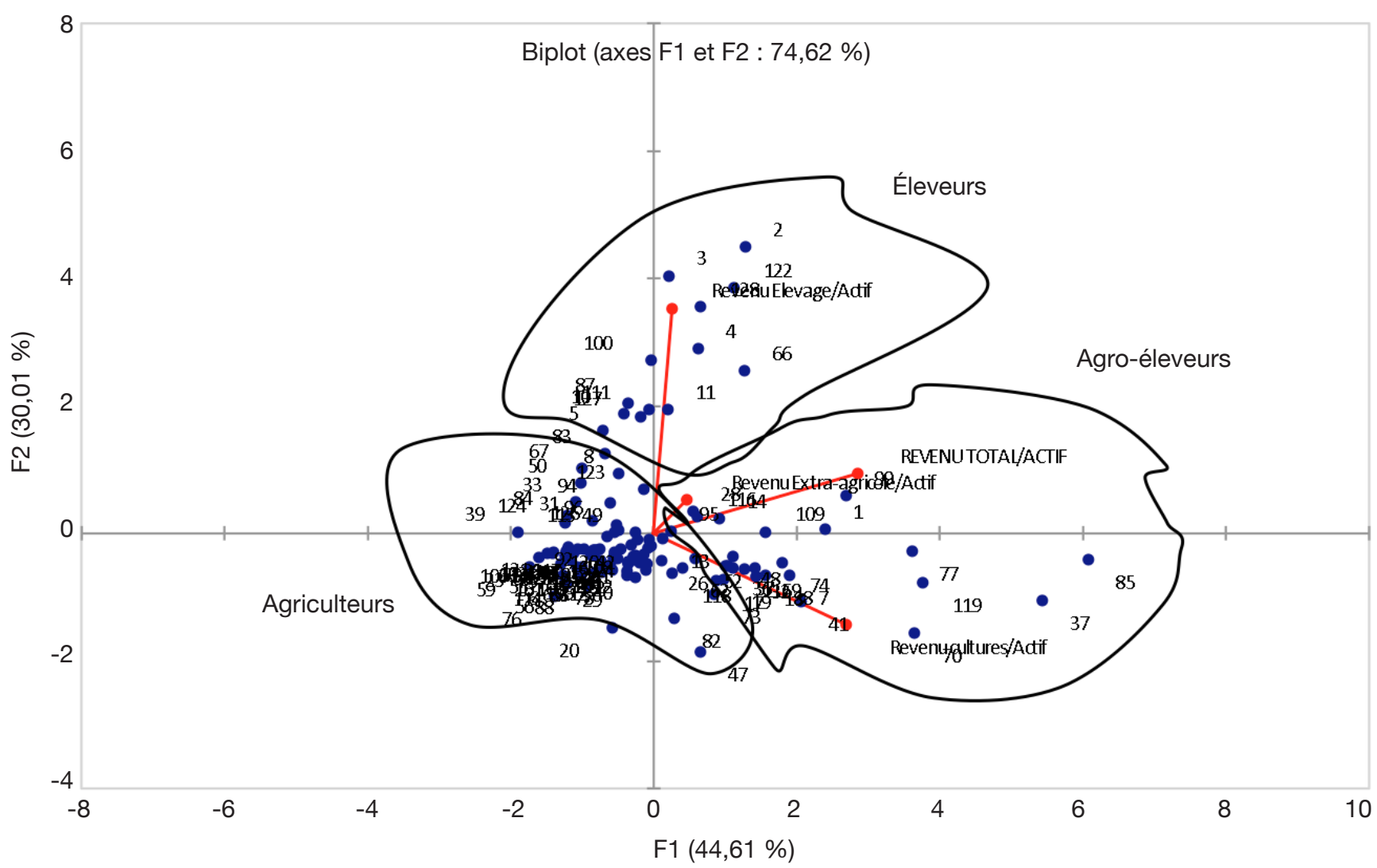

Figure 2. Distribution des exploitations sur les deux principaux axes selon leurs sources de revenus - Farms positionning on the two principal axis according to their incomes sources.

Tableau 2. Caractéristiques structurelles moyennes par type d'EAF - Average structural characteristics by farm type.

\begin{tabular}{llllll}
\hline & $\begin{array}{l}\text { Agro-éleveurs } \\
(\mathbf{n}=\mathbf{2 7})\end{array}$ & $\begin{array}{c}\text { Éleveurs } \\
(\mathbf{n = 1 7})\end{array}$ & $\begin{array}{c}\text { Agriculteurs } \\
(\mathbf{n}=\mathbf{7 6})\end{array}$ & $\boldsymbol{F}$ & $\boldsymbol{p}$-value \\
\hline Proportion (\%) & 22,5 & 14,2 & 63,3 & - & - \\
\hline Personnes (n) & $15,9^{\mathrm{a}} \pm 1,5$ & $13,4^{\mathrm{a}} \pm 1,9$ & $14,6^{\mathrm{a}} \pm 0,9$ & 0,529 & - \\
\hline Actifs (n) & $8,8^{\mathrm{a}} \pm 0,9$ & $6,9^{\mathrm{a}} \pm 1,1$ & $8,1^{\mathrm{a}} \pm 0,5$ & 0,781 & - \\
\hline Champs (n) & $3^{\mathrm{c}} \pm 0$ & $1^{\mathrm{a}} \pm 0$ & $2^{\mathrm{b}} \pm 0$ & 12,015 & $* * *$ \\
\hline Superficie cultivée (ha) & $16,4^{\mathrm{c}} \pm 1,3$ & $2,5^{\mathrm{a}} \pm 1,6$ & $7,9^{\mathrm{b}} \pm 0,8$ & 26,234 & $* * *$ \\
\hline Superficie cultivée par actif (ha) & $2,1^{\mathrm{c}} \pm 0,1$ & $0,4^{\mathrm{a}} \pm 0,2$ & $1^{\mathrm{b}} \pm 0,1$ & 34,456 & $* * *$ \\
\hline Unités de Bétail Tropical (n) & $11,9^{\mathrm{a}} \pm 2,3$ & $35,3^{\mathrm{b}} \pm 2,9$ & $8,6^{\mathrm{a}} \pm 1,4$ & 34,348 & $* * *$ \\
\hline Bœufs de trait (n) & $4,2^{\mathrm{c}} \pm 0,3$ & $2,4^{\mathrm{a}} \pm 0,4$ & $3,4^{\mathrm{b}} \pm 0,2$ & 5,846 & $* * *$ \\
\hline Charrues (n) & $1,9^{\mathrm{b}} \pm 0,2$ & $1,2^{\mathrm{a}} \pm 0,2$ & $1,6^{\mathrm{ab}} \pm 0,1$ & 2,915 & $* *$ \\
\hline Charrettes (n) & $1,4^{\mathrm{a}} \pm 0,1$ & $1,5^{\mathrm{a}} \pm 0,4$ & $1,1^{\mathrm{a}} \pm 0,1$ & 1,616 & - \\
\hline Pulvérisateurs (n) & $2^{\mathrm{b}} \pm 0,2$ & 0 & $1,7^{\mathrm{b}} \pm 0,1$ & 5,161 & $* * *$ \\
\hline Tracteurs (n) & $1,5^{\mathrm{a}} \pm 0,3$ & 0 & $1^{\mathrm{a}} \pm 0,6$ & 0,600 & - \\
\hline Botteleuses (n) & $1^{\mathrm{a}} \pm 0,5$ & $1,5^{\mathrm{a}} \pm 0,4$ & $1^{\mathrm{a}} \pm 0,4$ & 0,600 & - \\
\hline Fosses fumières & $2^{\mathrm{a}} \pm 0,2$ & $1,3^{\mathrm{a}} \pm 0,5$ & $1,5^{\mathrm{a}} \pm 0,1$ & 2,744 & - \\
\hline
\end{tabular}

Les différentes lettres sur la même ligne indiquent des différences significatives entre les variables - the different letters on the same line indicate significant differences between the variables ; - : non significatif - not significant $; * *: p<0,05 ; * * *: p<0,001$. 
agro-éleveurs cultivent les plus grandes superficies et sont plus équipés en matériel agricole. Les éleveurs détiennent plus d'animaux d'élevage (en UBT), cultivent de petites superficies et sont moins équipés.

\subsection{Pratiques de fertilisation des cultures}

Les pratiques de fertilisation sur les cultures pratiquées sur de grandes superficies (coton, maïs, sorgho et niébé) sont variées (Figure 3). Les plus grands utilisateurs d'engrais chimiques sont respectivement les agroéleveurs et les agriculteurs qui bénéficient de crédits intrants (engrais chimiques, herbicides, insecticides, etc.) grâce à la production du coton. Selon les résultats, les quantités moyennes de NPK-23-15-23 apportées par les EAF sur le coton $\left(144 \pm 21 \mathrm{~kg} \cdot \mathrm{ha}^{-1}\right)$ et NPK-1523-15 sur le maïs $\left(137 \pm 41 \mathrm{~kg} \cdot \mathrm{ha}^{-1}\right)$ et le sorgho $(95 \pm$ $43 \mathrm{~kg} \cdot \mathrm{ha}^{-1}$ ) sont inférieures à la dose recommandée $\left(150 \mathrm{~kg} \cdot \mathrm{ha}^{-1}\right)$ par les services techniques de l'agriculture pour ces trois spéculations. Pour l'urée 46-0-0 par contre, les quantités moyennes apportées (coton : $54 \pm$ $14 \mathrm{~kg} \cdot \mathrm{ha}^{-1}$; maïs : $60 \pm 27 \mathrm{~kg} \cdot \mathrm{ha}^{-1}$ et sorgho $58 \pm 27 \mathrm{~kg}$. $\mathrm{ha}^{-1}$ ) sont supérieures à la dose recommandée (urée : $46-0-0,50 \mathrm{~kg} \cdot \mathrm{ha}^{-1}$ pour coton et maïs et $0 \mathrm{~kg} \cdot \mathrm{ha}^{-1}$ pour le sorgho). La tendance de l'apport d'urée est plus importante sur le maïs chez les agro-éleveurs (64 \pm $\left.5 \mathrm{~kg} \cdot \mathrm{ha}^{-1}\right)$ que chez les agriculteurs $\left(60 \pm 3 \mathrm{~kg} \cdot \mathrm{ha}^{-1}\right)$ et chez les éleveurs $\left(54 \pm 7 \mathrm{~kg} \cdot \mathrm{ha}^{-1}\right)$, mais la différence n'est pas significative $(\mathrm{F}=0,704 ; p=0,497)$. Les agriculteurs ayant des revenus faibles et cultivant les plus petites superficies en coton, l'accès à l'urée au comptant est limité par son prix élevé (14400 FCFA. $\mathrm{kg}^{-1}$ contre 13200 FCFA pour le NPK en 2010/2011). Les éleveurs apportent les plus faibles quantités d'engrais chimiques sur les cultures. La couverture des besoins en FO est de $22 \%$ pour l'ensemble des EAF, soit $6543 \pm 9391 \mathrm{~kg}$ de FO mobilisée annuellement par exploitation. Cette couverture des besoins, fonction de la superficie cultivée et de la quantité de FO mobilisée, varie de $87 \%$ pour les éleveurs $(3189 \pm 2670 \mathrm{~kg})$, $14 \%$ pour les agriculteurs $(5861 \pm 1147 \mathrm{~kg})$ et $10 \%$ pour les agro-éleveurs $(9796 \pm 1814 \mathrm{~kg})$. La différence des quantités de FO mobilisées par type d'EAF reste non significative $(\mathrm{F}=2,573 ; p=0,08)$. Par contre, la quantité de FO apportée par hectare par les éleveurs $(1840 \pm 330 \mathrm{~kg})$ reste significativement différente $(\mathrm{F}=$ $5,141 ; p=0,008)$ par rapport aux agriculteurs $(760 \pm$ $140 \mathrm{~kg})$ et agro-éleveurs $(660 \pm 230 \mathrm{~kg})$ à cause de leurs faibles superficies cultivées et de leurs effectifs plus importants en animaux d'élevage. Compte tenu du déficit en FO, les EAF développent différentes stratégies pour optimiser son utilisation. Près de $86 \%$ des EAF fertilisent prioritairement le maïs, suivi du coton. Quand il s'agit de choisir entre les types de sol, la priorité revient aux sols gravillonnaires, suivis des sols sablonneux et des parties pauvres du champ. Des contrats de pâturage permettant aux animaux de pâturer les résidus de récolte dans les champs pendant un à trois mois contre fertilisation par les déjections sont aussi négociés par $8 \%$ de l'ensemble des EAF pour enrichir leurs sols.

\subsection{Pratiques d'alimentation des animaux}

Les EAF utilisent diverses ressources pour l'alimentation des animaux (Figure 4).

Le régime alimentaire des animaux pratiqué est la vaine pâture et la complémentation. Les ressources alimentaires endogènes distribuées aux animaux sont respectivement les pailles de céréales et de brousse, les sons de céréales, les fanes de légumineuses et les fruits des arbres. Les agriculteurs distribuent tous ces aliments à leurs animaux à raison de $315 \pm 32 \mathrm{~kg}$. $\mathrm{UBT}^{-1}$ par an de pailles de céréales, $79 \pm 23 \mathrm{~kg} \cdot \mathrm{UBT}^{1}$ a

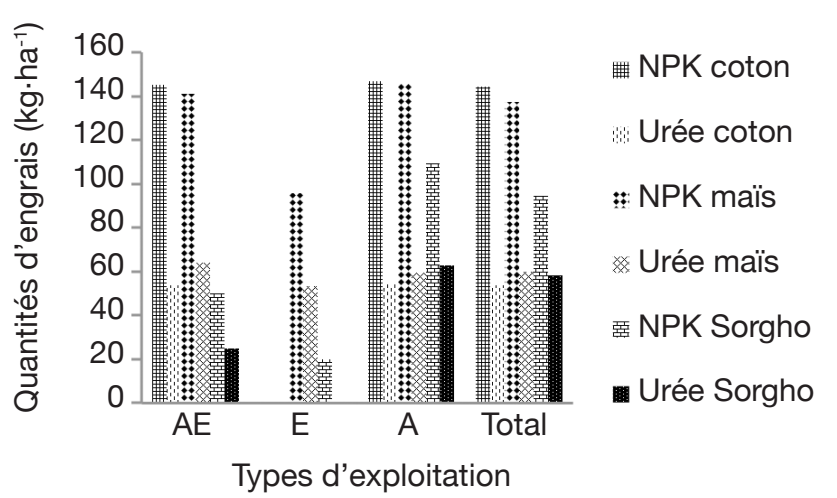

b

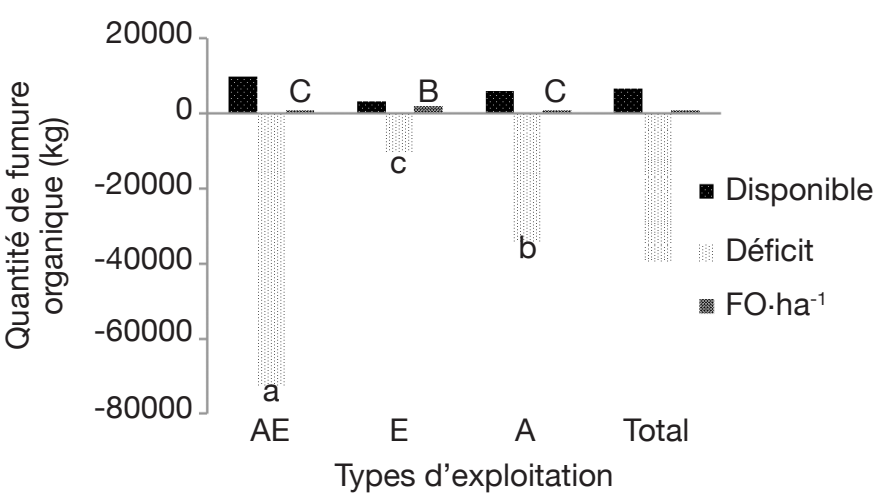

Figure 3. Pratique de fertilisation minérale (a) et organique (b) - Practice of mineral (a) and organic (b) fertilization.

Les histogrammes de même type portant différentes lettres diffèrent significativement au seuil de $5 \%$ - The histograms of the same type with different letters differ significantly at the threshold of $5 \%$. 
a

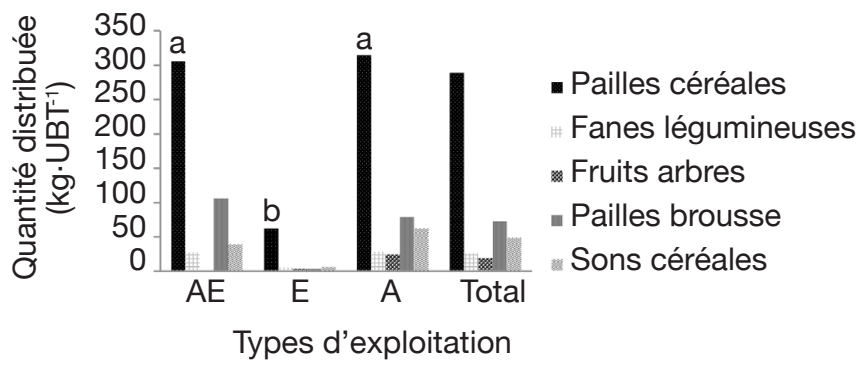

b

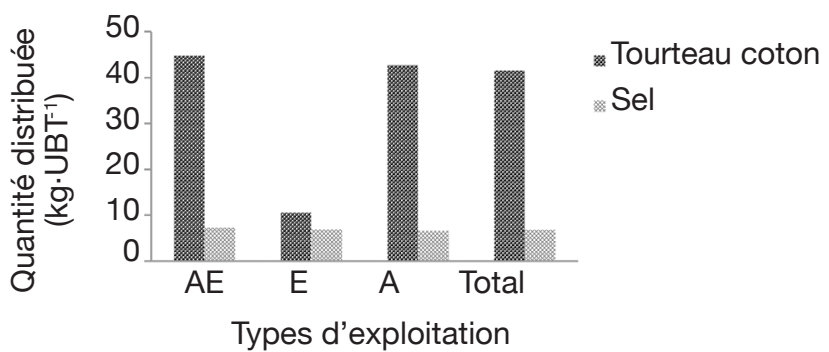

Figure 4. Pratiques d'alimentation des animaux avec les ressources endogènes (a) et les sous-produits agro-industriels (b) - Practices of animal food with endogenous resources (a) and agro-industrial by-products $(\boldsymbol{b})$.

par an de pailles de brousse, $62 \pm 31 \mathrm{~kg} \cdot \mathrm{UBT}^{-1}$ par an de sons de céréales, $29 \pm 4 \mathrm{~kg} \cdot \mathrm{UBT}^{-1}$ par an de fanes de légumineuses et $25 \pm 6 \mathrm{~kg} \cdot \mathrm{UBT}^{-1}$ par an de fruits d'arbres. Le nombre réduit de leur cheptel (8,6 UBT contre 11,9 pour les agro-éleveurs et 35,3 pour les éleveurs) leur facilite l'alimentation. En plus, leurs faibles revenus les obligent à entretenir leurs animaux principalement avec les ressources endogènes, surtout les bœufs de trait considérés par les exploitants comme des actifs pour leur rôle important dans le fonctionnement de l'EAF. Les agro-éleveurs n'utilisent pas les fruits des arbres mais plutôt le tourteau de coton en quantité importante dont l'accès est facilité par leurs revenus élevés $(p>0,05)$. Les éleveurs exploitent plus les pâturages naturels à cause du nombre important de leur cheptel. Leurs animaux restent longtemps aux pâturages et parcourent souvent de longues distances. Soixante-seize et demi pourcent des éleveurs pratiquent significativement la transhumance $(p<0,001)$. Seulement $7 \%$ de l'ensemble des EAF pratiquent les cultures fourragères et $18 \%$ l'embouche.

\subsection{Performances technico-économiques des EAF}

Les résultats du tableau 3 montrent une différence significative entre le rendement coton chez les agro-éleveurs $\left(1320 \pm 74 \mathrm{~kg} \cdot \mathrm{ha}^{-1}\right)$ et les agriculteurs $\left(974 \pm 48 \mathrm{~kg} \cdot \mathrm{ha}^{-1}\right)$; les éleveurs ne produisant pas le coton $(p<0,001)$. Pour le maïs, principale céréale cultivée par tous les types d'EAF, les agro-éleveurs présentent les meilleurs rendements $(2353 \pm 137 \mathrm{~kg}$. $\left.\mathrm{ha}^{-1}\right)$ comparativement aux deux autres types d'EAF $(p<0,001)$. Le maïs bénéficie de l'arrière-effet des engrais chimiques apportés sur le coton par les agro-éleveurs et les agriculteurs grâce à la rotation. En outre, le maïs étant le deuxième produit agricole destiné au marché chez les agro-éleveurs après le coton, ils utilisent les variétés améliorées (Espoir, Wari, Bondofa). La production laitière journalière par vache en saison pluvieuse chez les agro-éleveurs et les éleveurs est significativement élevée par rapport à celle des agriculteurs $(p<0,1)$. Par contre, en saison sèche, la différence des quantités de lait produites par vache par jour n'est pas statistiquement significative. Le cheptel bovin des agriculteurs est composé essentiellement de mâles pour la traction animale. La quantité de FO produite par UBT chez les éleveurs est faible, comparativement aux agro-éleveurs et agriculteurs $(p<0,05)$. La forte mobilité du troupeau des éleveurs cause des pertes de FO. Les agriculteurs dépensent $78500 \pm 4528$ FCFA par hectare cultivé et $30922 \pm 4273 \mathrm{FCFA}$ par UBT contre $50247 \pm$ 9573 et $5224 \pm 8915$ pour les éleveurs $(p<0,05)$ et $66758 \pm 7596$ FCFA et $24902 \pm 7209$ FCFA pour les agro-éleveurs. Cependant, les agriculteurs ont un revenu culture par hectare faible comparativement aux agro-éleveurs $(p<0,05)$ malgré leur consommation intermédiaire relativement élevée.

\subsection{Contraintes et opportunités d'intensification de la production agropastorale}

Selon les exploitations enquêtées (Tableau 4), les principaux facteurs limitant de la production agropastorale sont dans l'ordre la baisse de la fertilité des sols (qui se traduit par de faibles rendements agricoles), l'insuffisance des fourrages (qui se traduit par une faible production en lait et un amaigrissement des animaux), le cout élevé des intrants (NPK, urée, tourteau de coton, produits vétérinaires), le manque de terre et de main-d'œuvre. Le cout des intrants est perçu comme une contrainte plus par les agro-éleveurs et les agriculteurs que par les éleveurs, en raison de la culture du coton $(p<0,001)$. Heureusement, l'existence d'organisations paysannes efficaces, l'intervention du conseil à l'exploitation familiale et la présence des institutions de microfinance sont perçues comme des opportunités pour lever ces contraintes. En effet, l'efficacité des organisations paysannes (fonctionnement et bonne entente entre OP) facilite la concertation entre les utilisateurs des ressources pour réfléchir aux contraintes et chercher des pistes 
Tableau 3. Performances technico-économiques par type d'exploitation agricole familiale - Technical and economic performances by family farm type.

\begin{tabular}{|c|c|c|c|c|c|}
\hline & $\begin{array}{l}\text { Agro-éleveurs } \\
(\mathbf{n}=\mathbf{2 7})\end{array}$ & $\begin{array}{l}\text { Éleveurs } \\
(\mathbf{n}=17)\end{array}$ & $\begin{array}{l}\text { Agriculteurs } \\
(\mathbf{n}=76)\end{array}$ & $F$ & $p$-value \\
\hline \multicolumn{6}{|l|}{ Rendement $\left(\mathrm{kg} \cdot \mathrm{ha}^{-1}\right)$} \\
\hline Coton & $1320^{\mathrm{a}} \pm 74$ & 0 & $974^{\mathrm{b}} \pm 48$ & 15,499 & $* * *$ \\
\hline Maïs & $2353^{\mathrm{b}} \pm 137$ & $1889^{\mathrm{a}} \pm 178$ & $1856^{\mathrm{a}} \pm 82$ & 4,985 & $* * *$ \\
\hline Niébé & $491^{\mathrm{a}} \pm 86$ & $429^{a} \pm 137$ & $558^{\mathrm{a}} \pm 54$ & 0,510 & - \\
\hline \multicolumn{6}{|l|}{ Quantité lait/vache/jour (1) } \\
\hline Saison pluies & $1,7^{\mathrm{b}} \pm 0,3$ & $1,5^{\mathrm{b}} \pm 0,1$ & $1,1^{\mathrm{a}} \pm 0,1$ & 3,098 & $*$ \\
\hline Saison sèche & $1^{\mathrm{a}} \pm 0,3$ & $0,7^{\mathrm{a}} \pm 0,1$ & $0,5^{\mathrm{a}} \pm 0,1$ & 1,425 & - \\
\hline FO produite/UBT $(\mathrm{kg})$ & $931^{\mathrm{b}} \pm 172$ & $173^{a} \pm 235$ & $858^{\mathrm{b}} \pm 111$ & 3,976 & $* *$ \\
\hline \multicolumn{6}{|c|}{ Consommation intermédiaire (FCFA par an) } \\
\hline Culture (ha) & $66758^{\mathrm{ab}} \pm 7596$ & $50247^{\mathrm{a}} \pm 9573$ & $78500^{\mathrm{b}} \pm 4528$ & 3,849 & $* *$ \\
\hline Élevage (UBT) & $24902^{\mathrm{ab}} \pm 7209$ & $5224^{\mathrm{a}} \pm 8915$ & $30922^{b} \pm 4273$ & 3,389 & $* *$ \\
\hline Produit brut total/actif (FCFA) & $603400^{c} \pm 31553$ & $395637^{\mathrm{b}} \pm 39764$ & $232049^{a} \pm 1807$ & 52,294 & $* * *$ \\
\hline \multicolumn{6}{|l|}{ Revenu net (FCFA par an) } \\
\hline Total & $3327748^{c} \pm 234708$ & $1969412^{b} \pm 295791$ & $985515^{\mathrm{a}} \pm 139895$ & 37,412 & $* * *$ \\
\hline Total/actif & $415624^{c} \pm 20110$ & $310738^{b} \pm 25343$ & $115672^{\mathrm{a}} \pm 11986$ & 91,139 & $* * *$ \\
\hline Culture & $3033722^{c} \pm 204378$ & $277544^{a} \pm 257568$ & $851791^{\mathrm{b}} \pm 121818$ & 50,548 & $* * *$ \\
\hline Élevage & $63748^{a} \pm 80489$ & $1657750^{\mathrm{b}} \pm 101436$ & $8484^{a} \pm 47975$ & 111,644 & $* * *$ \\
\hline Extra-agricole & $518125^{\mathrm{a}} \pm 133492$ & $193333^{a} \pm 266985$ & $328216^{a} \pm 85871$ & 0,953 & - \\
\hline Culture par ha & $198177^{b} \pm 13172$ & $81345^{\mathrm{a}} \pm 16600$ & $105052^{a} \pm 7851$ & 22,047 & $* * *$ \\
\hline Part Élevage RA (\%) & $47,9^{\mathrm{a}} \pm 34,8$ & $86,7^{\mathrm{a}} \pm 73,2$ & $1,3^{\mathrm{a}} \pm 62,9$ & 0,406 & - \\
\hline Part Coton RA $(\%)$ & $110,4^{\mathrm{a}} \pm 8,8$ & 0 & $90,8^{a} \pm 13,6$ & 1,461 & - \\
\hline
\end{tabular}

FO : fumure organique - organic matter; RA : revenu agricole - agricultural income; les différentes lettres sur la même ligne indiquent des différences significatives entre les variables - the different letters on the same line indicate significant differences between the variables ; $: \mathrm{p}<0,1 ; * *: \mathrm{p}<0,05 ; * * *: \mathrm{p}<0,001 ;-$ : non significatif - not significant $; 1$ Euro $=655,957 \mathrm{~F}$ CFA.

de solutions à l'échelle du terroir. Les agents de vulgarisation contribueraient, par leurs connaissances et expériences, à la recherche de solutions. Quant aux institutions de microfinance, elles faciliteraient la mise en œuvre de solutions en accordant aux producteurs les moyens financiers nécessaires à crédit.

\section{DISCUSSION}

\subsection{Des typologies d'EAF qui se ressemblent en zone cotonnière}

La typologie des EAF basée sur les revenus met en évidence trois classes d'EAF : les exploitations à faible revenu cultures (agriculteurs), à fort revenu cultures (agro-éleveurs) et celles à revenu élevage (éleveurs). À partir des critères de structures des EAF, des typologies semblables avaient été établies dans la zone cotonnière ouest du Burkina Faso et au Mali-sud (Djouara et al., 2006 ; Vall et al., 2006). En effet, Traoré et al. (2013) montrent que les performances technico-économiques, la structure et les pratiques de production des EAF en zone cotonnière sont positivement corrélées.

Contrairement aux études précédentes limitées à la caractérisation structurelle des EAF, le présent article met en relation la structure et le fonctionnement (revenus, pratiques de production agropastorale).

Les EAF d'agro-éleveurs sont celles qui utilisent intensément les intrants chimiques et la traction animale sur de grandes superficies, comme la SOFITEX et l'UNPCB le recommandent depuis plusieurs décennies. Elles ont aussi un cheptel important, alimenté surtout avec du tourteau de coton et peu de résidus de culture et de cultures fourragères. Elles présentent les meilleurs revenus et rendements coton/maïs. Ce sont les «Producteurs Pilotes de Coton» promus par la SOFITEX pour encourager la production cotonnière 
Tableau 4. Perceptions des contraintes et opportunités de production agricole - Perceptions of the constraints and agricultural production appropriatenesses.

\begin{tabular}{|c|c|c|c|c|c|c|}
\hline & $\begin{array}{l}\text { Agro-éleveurs } \\
(\mathbf{n}=\mathbf{2 7})\end{array}$ & $\begin{array}{l}\text { Éleveurs } \\
(\mathrm{n}=17)\end{array}$ & $\begin{array}{l}\text { Agriculteurs } \\
(\mathbf{n}=76)\end{array}$ & Total & $\chi^{2}$ & $p$-value \\
\hline \multicolumn{7}{|c|}{ Contraintes (\%) } \\
\hline Baisse de fertilité & & & & & 0,149 & - \\
\hline Oui & 96,3 & 94,1 & 96,1 & 95,8 & & \\
\hline Non & 3,7 & 5,9 & 3,9 & 4,2 & & \\
\hline Manque de terre & & & & & 2,058 & - \\
\hline Oui & 92,6 & 88,2 & 81,6 & 85,0 & & \\
\hline Non & 7,4 & 11,8 & 18,4 & 15,0 & & \\
\hline Manque de main-d'œuvre & & & & & 0,230 & - \\
\hline Oui & 70,4 & 76,5 & 71,1 & 71,7 & & \\
\hline Non & 29,6 & 23,5 & 28,9 & 28,3 & & \\
\hline Cout élevé des intrants & & & & & 15,459 & $* * *$ \\
\hline Oui & 100,0 & 64,7 & 92,1 & 90,0 & & \\
\hline Non & 0,0 & 35,3 & 7,9 & 10,0 & & \\
\hline Insuffisances de fourrages & & & & & 5,612 & - \\
\hline Oui & 96,3 & 94,1 & 92,1 & 93,3 & & \\
\hline Non & 3,7 & 5,9 & 7,9 & 6,7 & & \\
\hline \multicolumn{7}{|c|}{ Opportunités (\%) } \\
\hline Organisations paysannes efficaces & & & & & 4,462 & - \\
\hline Oui & 100,0 & 82,4 & 90,8 & 91,7 & & \\
\hline Non & 0,0 & 17,6 & 9,2 & 8,3 & & \\
\hline Présence d'institutions de microfinance & & & & & 1,142 & - \\
\hline Oui & 77,8 & 64,7 & 76,3 & 75,0 & & \\
\hline Non & 22,2 & 35,3 & 23,7 & 25,0 & & \\
\hline Intervention de la vulgarisation & & & & & 0,391 & - \\
\hline Oui & 88,9 & 82,4 & 86,8 & 86,7 & & \\
\hline Non & 11,1 & 17,6 & 13,2 & 13,3 & & \\
\hline
\end{tabular}

- : non significatif - not significant $; * * *: \mathrm{p}<0,001$.

(Bainville et al., 2009). Les agriculteurs représentant la majorité des EAF de la zone exploitent des superficies moyennes. Leurs revenus et les rendements des cultures sont faibles. Ils utilisent davantage les résidus de culture dans l'alimentation des animaux que les autres types d'EAF et produisent plus la fumure organique. Blanchard et al. (2011) ont montré que les petits agriculteurs intègrent fortement les cultures et l'élevage. Les EAF d'éleveurs cultivent de petites superficies et leurs pratiques en matière d'élevage sont encore essentiellement extensives (transhumance, peu de collecte de résidus de culture et d'utilisation de tourteaux). L'élevage extensif en vigueur dans la zone cotonnière ouest du Burkina Faso est source de conflits entre agriculteurs et éleveurs (Vall et al., 2011).
Cette vue d'ensemble des capacités structurelles, des pratiques de production et des revenus des EAF permet de mieux identifier les besoins de chaque type d'EAF.

\subsection{Forces et faiblesses des actions de vulgarisation et d'appuis-conseils reçus}

Dans les années 1960-1970, le modèle de la révolution verte, destiné à accroître la production agricole, a été promu en se fondant sur la diffusion de paquets technologiques standards (variétés améliorées, engrais chimiques, techniques culturales mécanisées, irrigation) accompagnée de politiques agricoles favorables à leur développement (vulgarisation agricole, recherche agronomique, subventions aux intrants, politiques 
des prix et/ou contrôle des importations de produits concurrençant les productions locales, etc.) (Faure, 2007). Dans l'ouest du Burkina Faso, les appuisconseils aux producteurs de coton étaient basés sur ce modèle de production, encore dominant de nos jours. Il a montré une capacité d'accroissement colossale de la production agricole et de la productivité de la terre et du travail par l'augmentation des superficies cultivées essentiellement (Dugué et al., 2011). Mais aujourd'hui, compte tenu de ses impacts négatifs sur les écosystèmes (dégradation des sols, extension des superficies cultivées, réduction des espaces de jachères et de parcours naturels), de la nécessité de moyens financiers importants (achat d'intrants et de machines) et du désengagement des États de l'agriculture tant au niveau de l'accompagnement des producteurs (conseil, crédit, commercialisation) que des politiques de régulation sectorielles et nationales, on s'interroge de plus en plus sur la durabilité environnementale de ce type d'agriculture (Pretty et al., 2011). Il devient donc nécessaire de développer des pratiques de production agricole durable (Blanchard et al., 2011 ; Coulibaly et al., 2012).

\subsection{Besoins d'accompagnement complémentaires communs aux trois types d'EAF}

Pour limiter les conflits entre agriculteurs et éleveurs et l'utilisation d'engrais chimiques (de plus en plus chers), les trois types d'EAF seraient concernés par des accompagnements sur la gestion des ressources de l'exploitation (revenus, terre, animaux). Les EAF doivent utiliser rationnellement leurs revenus pour réduire leur dépendance aux crédits agricoles. Les animaux doivent être soignés par des professionnels et alimentés davantage avec des ressources endogènes. Sur les bonnes pratiques de gestion de la fertilité des sols, il s'agira de développer des techniques de production de la fumure organique en tas, dans les fosses et les parcs améliorés adaptés à la diversité des capacités structurelles des EAF. La facilitation de l'adoption de ces techniques améliorera quantitativement et qualitativement la FO et soutiendra la production agricole durable (Blanchard et al., 2014). En outre, les légumineuses fourragères peuvent être associées aux céréales (maïs/niébé, maïs/mucuna, etc.) pour faciliter la fixation de l'azote atmosphérique et l'alimentation des ruminants. Des baisses de rendements pour la principale culture ont été observées sur les cultures associées comparativement à la monoculture au Bénin et au Burkina Faso, mais elles permettent de diversifier la production et de réduire la contrainte de terres (Azontondé, 1993 ; Coulibaly, 2012). Sur l'agroforesterie, il s'agira de valoriser le rôle de l'arbre dans les systèmes de cultures en augmentant la densité d'espèces arborées utiles pour les sols, l'homme et les animaux (Faidherbia albida, Vitellaria paradoxa, Gliricidia sepium, etc.). Des expérimentations d'activités de plantation et de régénération assistées réalisées dans la zone cotonnière ouest du Burkina Faso en 2010 et 2011 ont donné des résultats encourageants (Coulibaly, 2012). Les techniques de conservation des eaux et sols et de défense/restauration des sols (cordons pierreux, diguette, zaï mécanisé, etc.) peuvent soutenir ces pratiques écologiques et atténuer les effets de la variabilité climatique (Ouédraogo et al., 2010). Une étude de l'organisation indienne Development Research Communication and Services Center (DRCSC) révèle un accroissement des revenus dans $64 \%$ des cas, avec au moins un doublement dans $44 \%$ des cas chez des exploitations agricoles ayant mis en œuvre des pratiques agro-écologiques en Inde (Levard et al., 2013).

\subsection{Besoins d'accompagnement spécifiques à chaque type}

Les agro-éleveurs auraient besoin d'accompagnement pour développer davantage les cultures fourragères, la production laitière en saison sèche, l'embouche et optimiser la répartition des ressources de l'EAF entre l'élevage et les cultures pour réduire la consommation d'intrants chimiques. La diversification de leurs cultures selon les opportunités du marché s'avère nécessaire pour sécuriser leurs revenus. L'accompagnement des agriculteurs doit porter sur l'amélioration de la valeur nutritive des résidus de récolte pour les animaux de trait. La promotion de variétés améliorées auprès de ces derniers augmenterait leur rendement en céréales dont l'excédent pourrait être mis sur le marché.

Les bonnes pratiques de gestion de grands effectifs de troupeaux, le développement des cultures fourragères pour l'embouche et la production laitière intéresseraient plus les éleveurs. Le prix du litre de lait peut atteindre 400 FCFA en saison sèche (Koutou, 2012) et le taux de rentabilité de l'investissement pour l'embouche d'un bovin, $46 \%$. L'élevage des agriculteurs est limité aux animaux de trait. L'état corporel et sanitaire de ces animaux reste une préoccupation majeure de ces derniers, surtout en début de campagne (Vall et al., 2006).

\subsection{Opportunités d'intensification durable}

Dans un contexte où les couts des intrants de synthèse augmentent et où les terres agricoles et pastorales deviennent rares, les EAF doivent innover (Faure, 2007). Des potentialités d'intensification de la production (variétés améliorées, intégration cultures élevages, existence des organisations paysannes, etc.) restent encore sous-valorisées (Vall et al., 2011 ; Coulibaly, 2012 ; Blanchard et al., 2014). Il importe 
de les exploiter pour améliorer durablement la sécurité alimentaire et les revenus des EAF.

\section{CONCLUSIONS}

Dans la zone cotonnière ouest du Burkina Faso, les différents appuis-conseils fournis aux exploitations agricoles familiales, essentiellement basés sur des formes d'intensification conventionnelles, ont tenu très peu compte de la diversité des exploitations et de leurs besoins d'accompagnements évolutifs. Ce modèle de production conventionnel ayant aujourd'hui atteint ses limites sur le capital productif, l'amélioration des systèmes de production nécessite des appuis-conseils diversifiés, adaptés et durables.

Cette étude a permis d'identifier trois types d'EAF à partir des sources et montants des revenus. La caractérisation des performances technicoéconomiques, des pratiques de production et des données sur les structures des EAF de chacun de ces types a mis en évidence leurs points faibles et leurs points forts. Ces résultats ont permis d'identifier des besoins d'accompagnement adaptés aux différents types d'EAF et complémentaires des accompagnements dont les EAF bénéficient déjà.

\section{Abréviations}

EAF : exploitation agricole familiale

GE : groupement d'éleveurs

GPC : groupement de producteurs de coton

$\mathrm{GV}$ : groupement villageois

IE : intensification écologique

\section{Remerciements}

Le dispositif de recherche et d'enseignement en partenariat sur "l'Intensification écologique et Conception des innovations dans les Systèmes Agro-Sylvo Pastoraux de l'Afrique de l'Ouest »(DP-ASAP : CIRDES, INERA,IDR/UPB,CIRAD) a servi de cadre à la réalisation de ce travail. Il a été financé par l'Ambassade de France au Burkina Faso et AusAid via le projet CORAF Options d'Intensification Durable. Les auteurs remercient tous les chercheurs du DP-ASAP et les bailleurs de fonds. Nous sommes également reconnaissants aux producteurs de Koumbia et de Gombèlèdougou pour leur accueil et leur franche collaboration.

\section{Bibliographie}

Abt V., Pierreval H., Lardon S. \& Steffe J., 2006. Modéliser le fonctionnement et l'organisation des exploitations agricoles : quelles méthodes pour le secteur agricole ? In : Sixième conférence francophone de modélisation et Simulation MOSIM'06, 3-5 avril 2006, Rabat, Maroc.
AICB (Association Interprofessionnelle du Coton du Burkina Faso), 2008. Note d'information sur la filière coton au Burkina Faso. Ouagadougou : Centre d'analyse des politiques économique et sociale (CAPES).

Azontondé A., 1993. Dégradation et restauration des terres de barre (sols ferralitiques faiblement désaturés argilosableux) au Bénin. Cah. Orst. Ser. Pédol., 28, 217-226.

Bainville S. \& Dufumier M., 2009. Diversité des exploitations agricoles en zone cotonnière du Burkina Faso: synthèse des études régionales conduites entre avril et septembre 2009. Paris : AFD.

Banque mondiale, 2008. L'agriculture au service $d u$ développement. Rapport sur le développement dans le monde. Washington : Banque mondiale.

BEAER (Bureau d'études et d'aménagement de l'espace rural), 2014. Plan communal de développement de Koumbia, horizon 2015-2019. Rapport diagnostic.

Blanchard M. et al., 2011. Contribution de l'intégration agriculture-élevage à l'intensification écologique des systèmes agro-sylvo-pastoraux: le cas du Mali-Sud. In : Vall E., Andrieu N., Chia E. \& Nacro H.B. Actes du colloque Partenariat, modélisation, expérimentations: quelles leçons pour la conception de l'innovation et l'intensification écologique?, novembre 2011, BoboDioulasso, Burkina Faso. Cirad, https://hal.archivesouvertes.fr/hal-00718658, (26/10/2015).

Blanchard M. et al., 2014. Diversité de la qualité des engrais organiques produits par les paysans d'Afrique de l'Ouest : quelles conséquences sur les recommandations de fumure? Biotechnol. Agron. Soc. Environ., 18(4), 512-523.

Capillon A., 1993. Typologie des exploitations agricoles. Contribution à l'étude des problèmes techniques. Thèse de doctorat en sciences agronomiques : INA-PG, Paris (France).

Cassman K.G., 1999. Ecological intensification of cereal production systems: yield potential, soil quality, and precision agriculture. PNAS, 96, 5952-5959.

Chevassus-au-Louis B., 2006. Refonder la recherche agronomique : leçons du passé, enjeux du siècle. Leçon inaugurale du Groupe ESA, Angers, France.

Chevassus-au-Louis B. \& Griffon M., 2008. La nouvelle modernité : une agriculture productive à haute valeur écologique. In: Club Déméter. Le Déméter 2008: économie et stratégies agricoles. Paris : Club Déméter, 7-48.

Christiaensen L., 1998. Mali case study: methodology and descriptives. Washington: International Food Policy Research Institute.

CIRDES, 2008. Diagnostic agropastoral du village de Koumbia, projet Fertipartenaires. Bobo-Dioulasso, Burkina Faso : CIRDES.

Coulibaly K., 2012. Analyse des facteurs de variabilité des performances agronomiques et économiques des cultures et de l'évolution de la fertilité des sols dans les systèmes agropastoraux en milieu soudanien du Burkina 
Faso : approche expérimentale chez et par les paysans. Thèse de doctorat unique : Université Polytechnique de Bobo-Dioulasso (Burkina Faso).

Coulibaly K., Vall E., Autfray P. \& Sedogo P.M., 2012. Performance technico-économique des associations maïs/niébé et maïs/mucuna en situation réelle de culture au Burkina Faso : potentiels et contraintes. Tropicultura, 30(3), 147-154

Djouara H., Bélières J.F. \& Kébé D., 2006. Les exploitations agricoles familiales de la zone cotonnière du Mali face à la baisse des prix du coton-graine. Cah. Agric., 15(1), 64-71.

Dugué P. et al., 2011. L'intensification écologique : réflexions pour la mise en pratique de ce concept dans les zones de savane d'Afrique de l'Ouest. In: Vall E., Andrieu N., Chia E. \& Nacro H.B. Actes du séminaire Partenariat, modélisation, expérimentations : quelles leçons pour la conception de l'innovation et l'intensification écologique?, novembre 2011, BoboDioulasso, Burkina Faso. Cirad, https://hal.archivesouvertes.fr/hal-00718387, (27/10/2015).

Faure G., 2007. L'exploitation agricole dans un environnement changeant: innovation, aide à la décision et processus d'accompagnement. Dijon, France : Université de Bourgogne.

FENAB (Fédération nationale pour l'agriculture biologique), 2014. Initiative agriculture écologique biologique (AEB) au Sénégal. Mensuel Inf. Agric. Ecol. Biol., 00.

Ferraton N. \& Touzard I., 2009. Comprendre l'agriculture familiale: diagnostic des systèmes de production. Gembloux, Belgique: Les Presses agronomiques de Gembloux ; Wageningen, The Netherlands : CTA ; Versailles, France : Éditions Quæ.

Francois J.L., 2014. Avant-propos. Agricultures africaines : quelles mutations face aux défis et aux opportunités liés à la croissance démographique et à l'urbanisation ? In : Club Déméter. Le Déméter 2014 : Dossier Agricultures Africaines. Paris : Le Déméter, 78-94.

Griffon M., 2009. Pour des agricultures écologiquement intensives. La Tour d'Aigues, France: Éditions de l'Aube.

Hathie I. \& Ba C.O., 2014. Diversité et dynamique des agricultures ouest africaines: illustrations concrètes des mutations en cours. In : Club Déméter. Le Déméter 2014: dossier agricultures africaines. Paris: Le Déméter, 115-124.

IAC (Inter Academy Council), 2004. Realizing the promise and potential of African agriculture. Science and technology strategies for improving agricultural productivity and food security in Africa. Amsterdam, The Netherlands: IAC.

INSD (Institut National de la Statistique et de la Démographie), 2006. Recensement général de la population et de l'habitation du Burkina Faso. Résultats définitifs. Ouagadougou : INSD.

Koutou M.,2012. Analyse des chaînes de valeur des produits animaux. Bobo-Dioulasso, Burkina Faso : CIRDES.
Landais E., 1996. Typologies d'exploitations agricoles. Nouvelles questions, nouvelles méthodes. Écon. Rurale, 236, 3-15.

Landais E., 1999. Agriculture durable : les fondements d'un nouveau contrat social ? Courrier Env. Inra, 33, http:// www.inra.fr/dpenv/landac33.htm, (27/10/15).

Lankoandé G.D., 2013. L'exploitation agricole familiale au Burkina Faso. INADES-Formation.

Levard L. \& Apollin F., 2013. Répondre aux défis du XXI siècle avec l'agro-écologie: pourquoi et comment? Paris : Coordination SUD.

Mbétid-Bessane E. \& Havard M., 2013. Stratégies adaptatives et viabilité des exploitations agricoles familiales des savanes cotonnières d'Afrique centrale. Agron. Afr., 25(2), 171-185.

Ouédraogo M., Dembélé Y. \& Somé L., 2010. Perceptions et stratégies d'adaptation aux changements des précipitations: cas des paysans du Burkina Faso. Sécheresse, 21(2), 87-96

Phliponeau M. \& Guibert H., 2011. Système lignager, moteur de l'expansion de la culture du coton? Le cas des Bwa du Burkina Faso. Biotechnol.Agron. Soc. Environ., 15(3), 367-378.

Pretty J., Toulmin C. \& Williams S., 2011. Sustainable intensification: increasing productivity in African food and agricultural systems. London: Earthscan Publications

Traoré M., Nacro H.B., Ouédraogo D. \& Sanou M.R., 2013. Dynamique et performance économique des systèmes de production agricole à base de coton dans les villages de Karaborosso et de Kotoura (ouest du Burkina Faso). Sécheresse, 24, 115-128.

Vall E., 2004. Proposition de zonages agropastoraux de l'Ouest du Burkina Faso et de la province de Houet. Bobo-Dioulasso, Burkina Faso : Cirdes-Urpan.

Vall E., Dugué P. \& Blanchard M., 2006. Le tissage des relations agriculture-élevage au fil du coton, 1990-2005. Cah. Agric., 15(1), 72-79.

Vall E. et al., 2011. Intégration agriculture-élevage et intensification écologique dans les systèmes agrosylvopastoraux de l'Ouest du Burkina Faso, province du Tuy. In: Vall E., Andrieu N., Chia E. \& Nacro H.B. Partenariat, modélisation, expérimentations: quelles leçons pour la conception de l'innovation et l'intensification écologique?, Novembre 2011, BoboDioulasso, Burkina Faso. Cirad, https://hal.archivesouvertes.fr/hal-00718613/document, (26/10/2015).

Vayssires J., Vigne M., Alary V. \& Lecomte P., 2011. Integrated participatory modelling of actual farms to support policy making on sustainable intensification. Agric. Syst., 104, 146-161.

Wezel A. et al., 2009. Agroecology as a science, a movement and a practice. A review. Agron. Sustainable Dev., 29, 503-515.

(41 réf.) 